\title{
Cavitands with Revolving Doors Regulate Binding Selectivities and Rates in Water
}

\section{Supporting Information}

Richard J. Hooley, Hillary J. Van Anda and Julius Rebek, Jr.*

The Skaggs Institute for Chemical Biology and the Department of Chemistry, The Scripps Research Institute MB-26, 10550 North Torrey Pines Rd., La Jolla, CA 92037.

jrebek@scripps.edu

\section{General Information}

${ }^{1} \mathrm{H}$ and ${ }^{13} \mathrm{C}$ NMR spectra were recorded on a Bruker DRX-600 spectrometer with a $5 \mathrm{~mm}$ QNP probe. 2D spectra were recorded on a Bruker DRX-600 spectrometer with a $5 \mathrm{~mm}$ BBI XYZ-gradient inverse probe. Proton $\left({ }^{1} \mathrm{H}\right)$ chemical shifts are reported in parts per million $(\delta)$ with respect to tetramethylsilane $(\mathrm{TMS}, \delta=0)$, and referenced internally with respect to the protio solvent impurity. Deuterated NMR solvents were obtained from Cambridge Isotope Laboratories, Inc., Andover, MA, and used without further purification. Hydrocarbon guests (isobutane, n-pentane, $n$-hexane, cyclopentanecycloheptane, <99\%) and methyl 4-cyanomethylbenzoate were obtained from Aldrich Chemical Company, St. Louis, MO and were used as received. Anhydrous solvents were obtained from Aldrich Chemical Company, St. Louis, MO and were used as received. Molecular modeling (semi-empirical calculations) was carried out using the AM1 force field with the solvation (dielectric) setting for water as implemented by Spartan. Cavitand 1 was synthesized according to the procedure described in: Biros, S.M., Ullrich, E.C., Hof, F., Trembleau, L., Rebek, J.. J. Am. Chem. Soc. 2004, 126, 2870-2876. Octaamine cavitand, $\mathrm{HCl}$ salt was synthesized according to the procedure described in: Rafai Far, A.; Shivanyuk, A.; Rebek, J. J. Am. Chem. Soc. 2002, 124, 2854-2855. 


\section{Synthesis of New Compounds}<smiles>CCOC(=N)Cc1ccc(C(=O)O)cc1</smiles>

\section{Methyl 4-(2-ethoxy-2-iminoethyl)benzoate hydrochloride 5:}

To an oven-dried, $100 \mathrm{~mL}$ round-bottomed flask equipped with a magnetic stirrer was added methyl 4-cyanomethylbenzoate $(6.40 \mathrm{~g}, 36.6 \mathrm{mmol})$, anhydrous ethanol (53 mmol, $3.0 \mathrm{~mL})$ and anhydrous toluene $(50 \mathrm{~mL})$. The mixture was cooled to $-10{ }^{\circ} \mathrm{C}$ and hydrogen chloride gas was bubbled into the solution for $20 \mathrm{~min}$. The flask was sealed, and stirred at $23{ }^{\circ} \mathrm{C}$ for $16 \mathrm{~h}$, by which time a white precipitate had formed. Anhydrous ether $(200 \mathrm{~mL})$ was added and the white solid removed by vacuum filtration. The solid was quickly washed with anhydrous ether $(2 \times 50 \mathrm{~mL})$ and dried under vacuum to yield 5 (7.34 g, $78 \%$ ) which was used without further purification. ${ }^{1} \mathrm{H}$ NMR (600 MHz, DMSO- $\left.d_{6}\right)$ $\delta 1.27(\mathrm{t}, \mathrm{J}=7.2 \mathrm{~Hz}, 3 \mathrm{H}) ; 3.86(\mathrm{~s}, 3 \mathrm{H}) ; 4.12(\mathrm{~s}, 2 \mathrm{H}) ; 4.41(\mathrm{q}, \mathrm{J}=7.2 \mathrm{~Hz}, 2 \mathrm{H}) ; 7.52(\mathrm{~d}, \mathrm{~J}=$ $8.4 \mathrm{~Hz}, 2 \mathrm{H}) ; 7.96(\mathrm{~d}, \mathrm{~J}=8.4 \mathrm{~Hz}, 2 \mathrm{H}) .{ }^{13} \mathrm{C}$ NMR $\left(150 \mathrm{MHz}, \mathrm{DMSO}-d_{6}\right) \delta 13.1 ; 38.2 ; 52.1$; $69.2 ; 129.0 ; 129.5 ; 129.6 ; 137.6 ; 165.8 ; 176.4$. ESIHRMS $m / z$ : calcd for $\mathrm{C}_{12} \mathrm{H}_{16} \mathrm{NO}_{3}$ $\left(\mathrm{M}+\mathrm{H}^{+}\right)$222.1125; found 222.1121. 


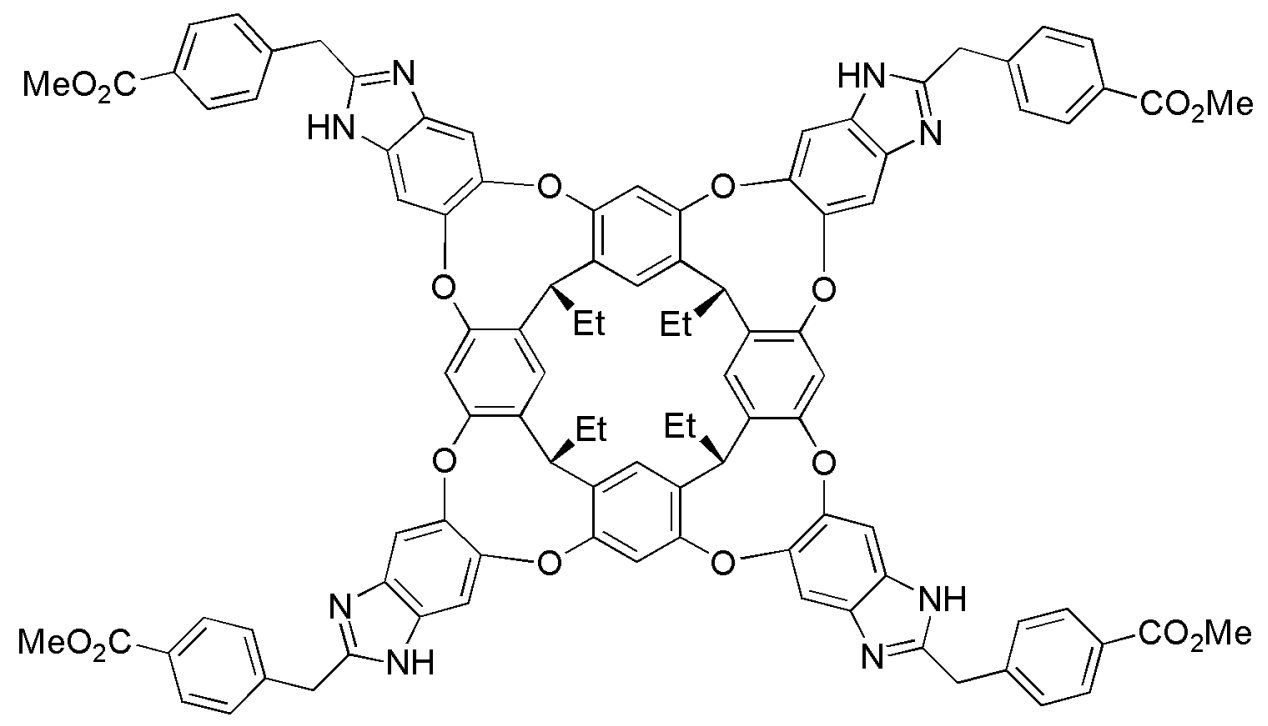

\section{Tetramethylbenzoate cavitand 7:}

To an oven-dried, $25 \mathrm{~mL}$ round-bottomed flask equipped with a magnetic stirrer and water-cooled condenser was added octaamine cavitand, $\mathrm{HCl}$ salt (200 mg, $0.172 \mathrm{mmol}$ ), imidate $5(1.03 \mathrm{mmol}, 265 \mathrm{mg})$ and anhydrous ethanol $(10 \mathrm{~mL})$. The mixture was placed under argon and heated to reflux for $14 \mathrm{~h}$. The solvent was removed by rotary evaporation and the resulting solid was suspended in $\mathrm{CH}_{2} \mathrm{Cl}_{2}(25 \mathrm{~mL})$. The suspension was filtered and washed with $\mathrm{CH}_{2} \mathrm{Cl}_{2}(3 \times 20 \mathrm{~mL})$, then dried under high vacuum to yield tetraester 7 (227 mg, 80\%) as an off-white solid. ${ }^{1} \mathrm{H}$ NMR (600 MHz, THF- $\left.d_{8} / \mathrm{D}_{2} \mathrm{O}, 3: 1\right)$ $\delta 0.93(\mathrm{t}, \mathrm{J}=7.8 \mathrm{~Hz}, 12 \mathrm{H}) ; 2.29(\mathrm{qn}, \mathrm{J}=7.8 \mathrm{~Hz}, 8 \mathrm{H}) ; 3.79$ (s, 12H); $4.22(\mathrm{~s}, 8 \mathrm{H}) ; 5.58$ (t, $\mathrm{J}=7.8 \mathrm{~Hz}, 4 \mathrm{H}) ; 7.37$ (s, 4H); 7.48 (d, J = 8.4 Hz, 8 H); 7.76 (s, 4H); 7.88 (d, J = 8.4 Hz, $8 \mathrm{H}) ; 8.04(\mathrm{~s}, 8 \mathrm{H})$. ESIHRMS $m / z$ : calcd for $\mathrm{C}_{100} \mathrm{H}_{81} \mathrm{~N}_{8} \mathrm{O}_{16}\left(\mathrm{M}+\mathrm{H}^{+}\right)$1649.5765; found 1649.5784 . 


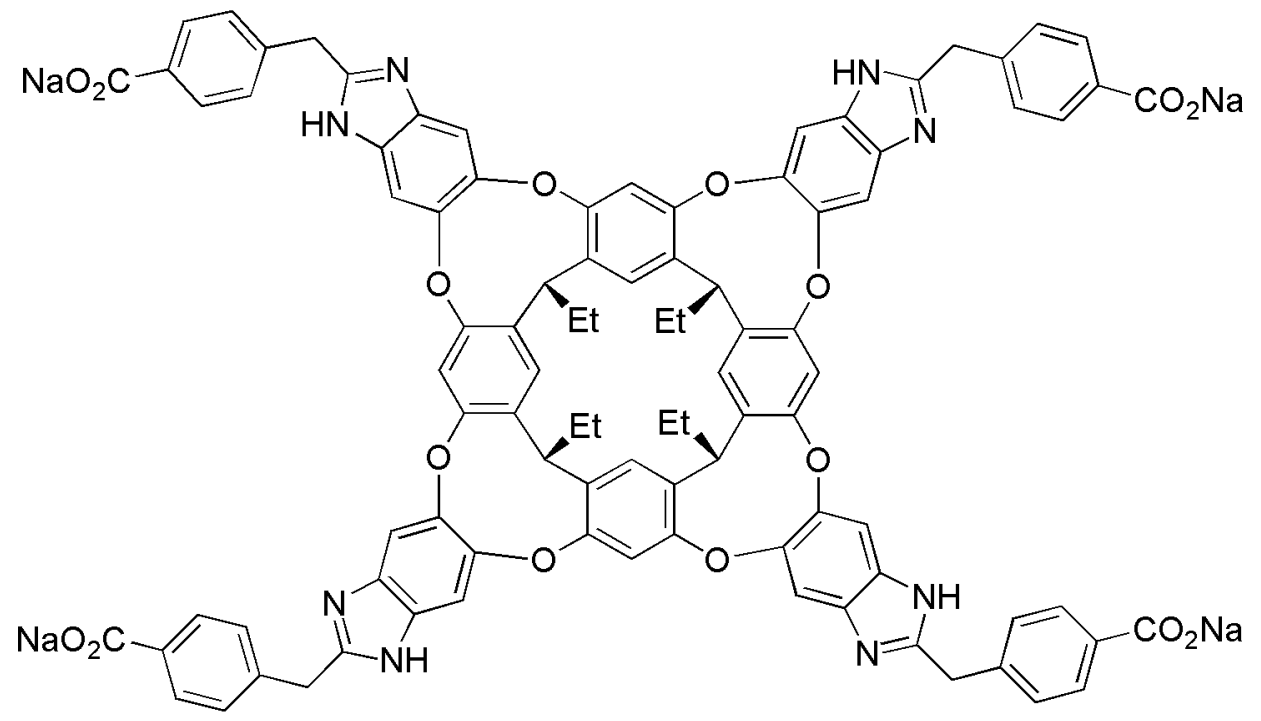

\section{Benzoate cavitand, tetrasodium salt 2:}

In a $50 \mathrm{~mL}$, round-bottomed flask, cavitand tetraester 7 (77 $\mathrm{mg}, 0.046 \mathrm{mmol})$ and $\mathrm{NaOH}$ (60 mg, $1.5 \mathrm{mmol})$ were dissolved in $\mathrm{THF} / \mathrm{H}_{2} \mathrm{O}\left(1: 1,10 \mathrm{~mL}\right.$ total) and stirred at $23{ }^{\circ} \mathrm{C}$ for $16 \mathrm{~h}$. The solvent was removed by rotary evaporation and lyophilization, yielding 2 as a yellow solid. ${ }^{1} \mathrm{H}$ NMR (600 MHz, $\left.\mathrm{D}_{2} \mathrm{O}\right) \delta 1.05$ (t, J = $\left.7.2 \mathrm{~Hz}, 12 \mathrm{H}\right) ; 2.46$ (qn, J = 7.2 Hz, $8 \mathrm{H}) ; 3.59(\mathrm{~s}, 8 \mathrm{H}) ; 5.59$ (t, J = 7.2 Hz, 4H); 6.50 (d, J = 7.2 Hz, $8 \mathrm{H}) ; 7.37$ (d, J = 7.2 Hz, $8 \mathrm{H}) ; 7.62(\mathrm{~s}, 4 \mathrm{H}) ; 7.83(\mathrm{~s}, 4 \mathrm{H}) ; 7.88(\mathrm{~s}, 8 \mathrm{H})$. ESIHRMS m/z: calcd for $\mathrm{C}_{96} \mathrm{H}_{71} \mathrm{~N}_{8} \mathrm{O}_{16}(\mathrm{M}-$ $\mathrm{H}^{+}$) 1591.4993; found 1591.4937.

\section{Selected NMR Experiments}

\section{Crude Calculation of Average Position of Benzoate Doors:}

Based upon the known $\Delta \delta$ values obtained for helically bound hydrocarbon guests in cavitand $\mathbf{1},{ }^{1}$ the position of the relevant protons $\mathrm{H}_{\mathrm{a}}$ and $\mathrm{H}_{\mathrm{b}}$ in cavitand $\mathbf{2}$ can be estimated. The observed change in chemical shift $\delta$ of $\mathrm{H}_{\mathrm{a}}$ between the "fully closed" position (derived from the spectra of $2 \cdot \mathrm{THF}, \mathbf{2} \bullet$ cyclopentane and $2 \cdot$ isobutane, $\delta\left(\mathrm{H}_{\mathrm{a}}\right)=6.50 \mathrm{ppm}$ ) and the "fully open" position (derived from the spectra of $\mathbf{2} \bullet n$-hexane and $\mathbf{2} \bullet$ transdecalin, $\left.\delta\left(\mathrm{H}_{\mathrm{a}}\right)=7.36 \mathrm{ppm}\right)$ is $\Delta \delta=-0.86 \mathrm{ppm}$. 
Hence if only one benzoate moiety resides over the cavity on average at any one time, this $\Delta \delta$ value corresponds to $1 / 4$ of the actual shielding experienced, or $-3.44 \mathrm{ppm}$. Similarly, if two benzoate moieties reside over the cavity on average at any one time, this $\Delta \delta$ value corresponds to $1 / 2$ the actual shielding experienced, or $-1.72 \mathrm{ppm}$. Sterics dictate that having 4 benzoates over the cavity at once is unlikely and a $\Delta \delta$ value of $-3.44 \mathrm{ppm}$ would correspond to a position for $\mathrm{H}_{\mathrm{a}}$ approximately at the position of $\mathrm{C}_{4}$ in Figure S1; again unlikely. A $\Delta \delta$ value for $\mathrm{H}_{\mathrm{a}}$ of $-1.72 \mathrm{ppm}$ would correspond to a position approximately at the position of $\mathrm{C}_{6}$ in Figure $\mathrm{S} 1$; this would allow the only the small guests (THF, cyclopentane and isobutane) to occupy the cavity without disturbing the doors, so an average of two benzoate moieties shielding the cavitand opening is the most likely scenario.
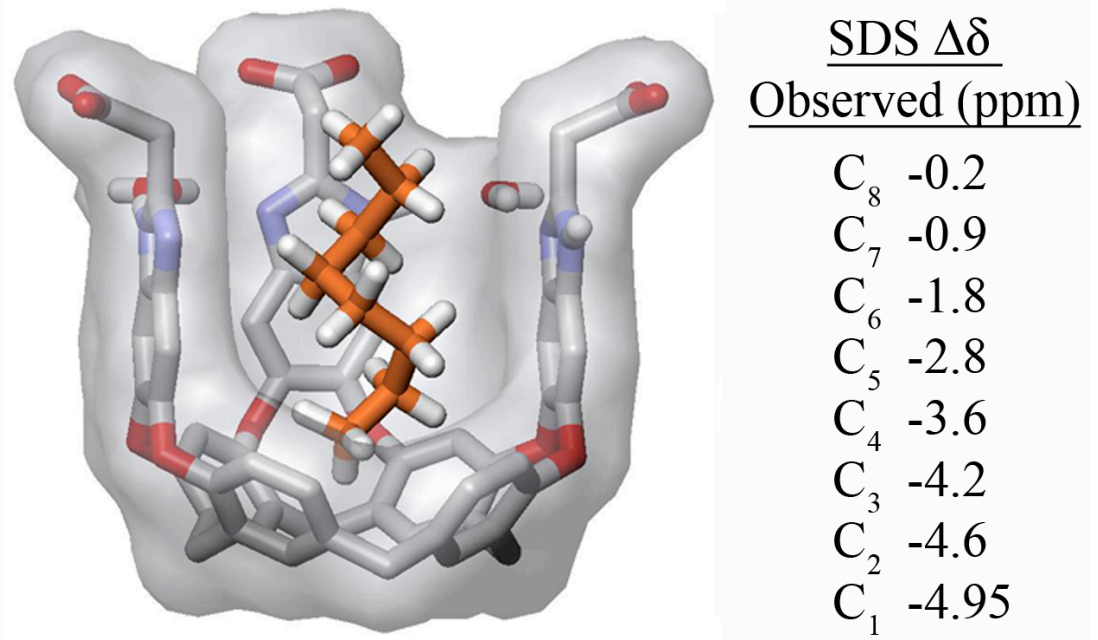

Figure S1. Depiction of the $\Delta \delta$ values obtained upon helical binding of hydrocarbons in cavitand 1. Actual values derived from binding of SDS. ${ }^{1}$

\section{Competition Between Cavitands 1 and 2:}

Cavitand $1\left(0.9 \mathrm{mg}, 6 \times 10^{-4} \mathrm{mmol}\right)$ was dissolved in water $(1 \mathrm{~mL})$ and 2 drops of cycloalkane (either cyclopentane or cyclohexane) was added. The suspension was sonicated for $30 \mathrm{~s}$ to effect extraction of the hydrocarbon and the solvent removed by rotary evaporation followed by drying under high vacuum ( 0.1 Torr). The resulting solid complex 1•cycloalkane was dissolved in $\mathrm{D}_{2} \mathrm{O}(500 \mu \mathrm{L})$. To this solution was added a solution of cavitand $2\left(1.0 \mathrm{mg}, 6 \times 10^{-4} \mathrm{mmol}\right)$ in $\mathrm{D}_{2} \mathrm{O}(100 \mu \mathrm{L})$ and after $30 \mathrm{~s}$ mild shaking to effect equilibration, the ${ }^{1} \mathrm{H}$ NMR spectrum was recorded. Integration of the 
guest peaks for $\mathbf{1} \bullet$ cycloalkane, $\mathbf{1} \cdot \mathrm{THF}, \mathbf{2} \bullet$ cycloalkane and $\mathbf{2} \cdot \mathrm{THF}$ gave relative populations of the complexes. Assuming that the binding affinity of THF for $\mathbf{1}$ and $\mathbf{2}$ is insignificant compared to that of the cycloalkanes (as observed), the relative binding constant $\mathrm{K}_{\text {rel }}$ can be calculated.

\section{Procedure for EXSY Experiments}

The EXSY spectra of complexes $\mathbf{1} \bullet$ cyclohexane and $\mathbf{2} \bullet$ cyclohexane were recorded at 300 $\mathrm{K}$ at $600 \mathrm{MHz}$ with the phase sensitive NOESY pulse sequence supplied with the Bruker software. Each of the 512 F1 increments was the accumulation of 40 scans. For each complex, two spectra were taken sequentially, one with $350 \mathrm{~ms}$ mixing time and then with $0 \mathrm{~ms}$ mixing time. The MestreC program (Mestrelab Research, Santiago de Compostela) was used to analyse the spectra. Before Fourier transformation, the FIDs were multiplied by a 90 sine square function in both the F2 and the F1 domain. $1 \mathrm{~K}_{-} 1 \mathrm{~K}$ real data points were used, with a resolution of $1 \mathrm{~Hz} /$ point. The rate constants $k$ were calculated using the EXSYCALC program (Mestrelab Research, Santiago de Compostela), see refs 2,3. 
NOESY Spectrum of 2•cyclohexane, $350 \mathrm{~ms}$ mixing time:

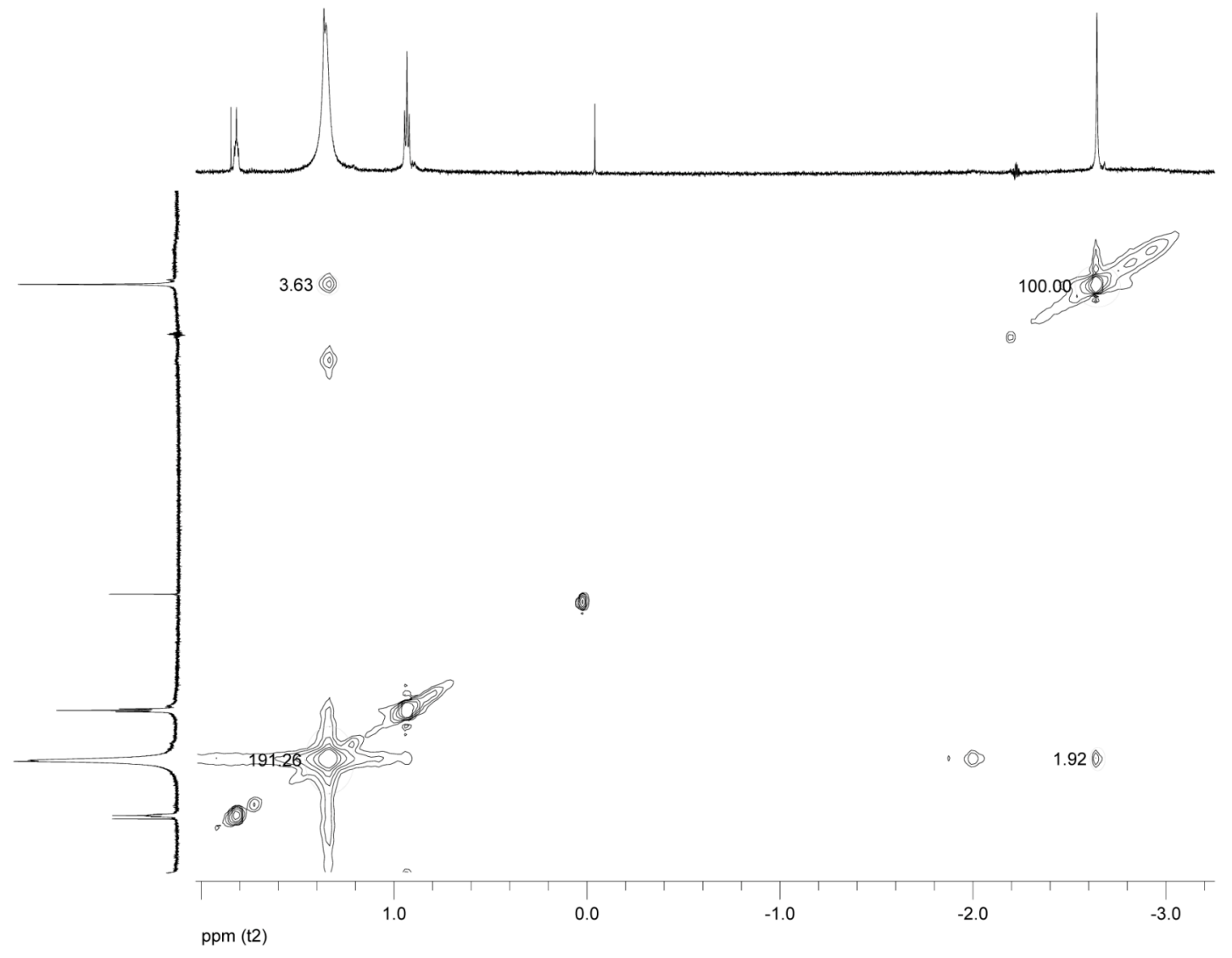


NOESY Spectrum of $2 \bullet$ cyclohexane, 0 ms mixing time:

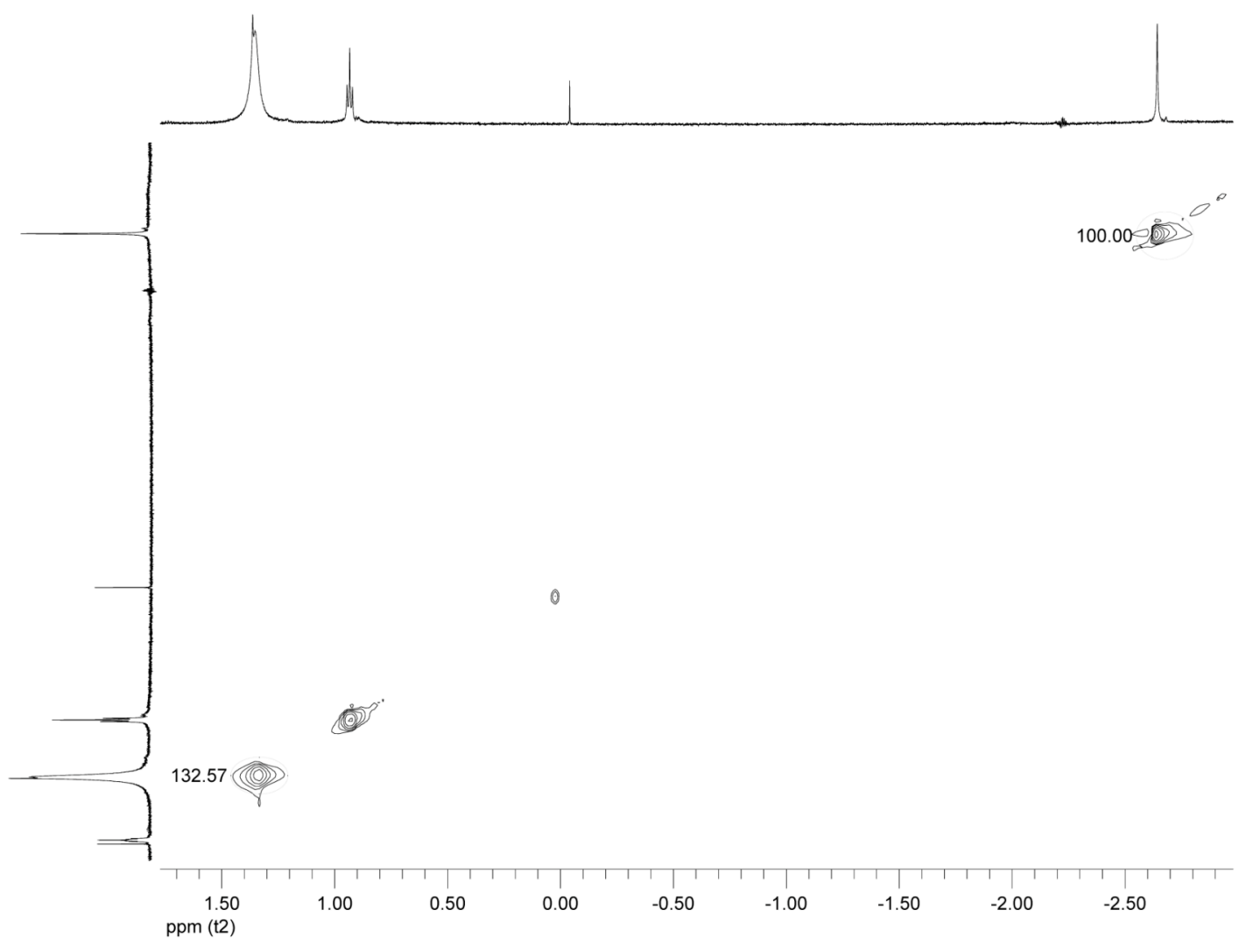


NOESY Spectrum of 1•cyclohexane, $350 \mathrm{~ms}$ mixing time:

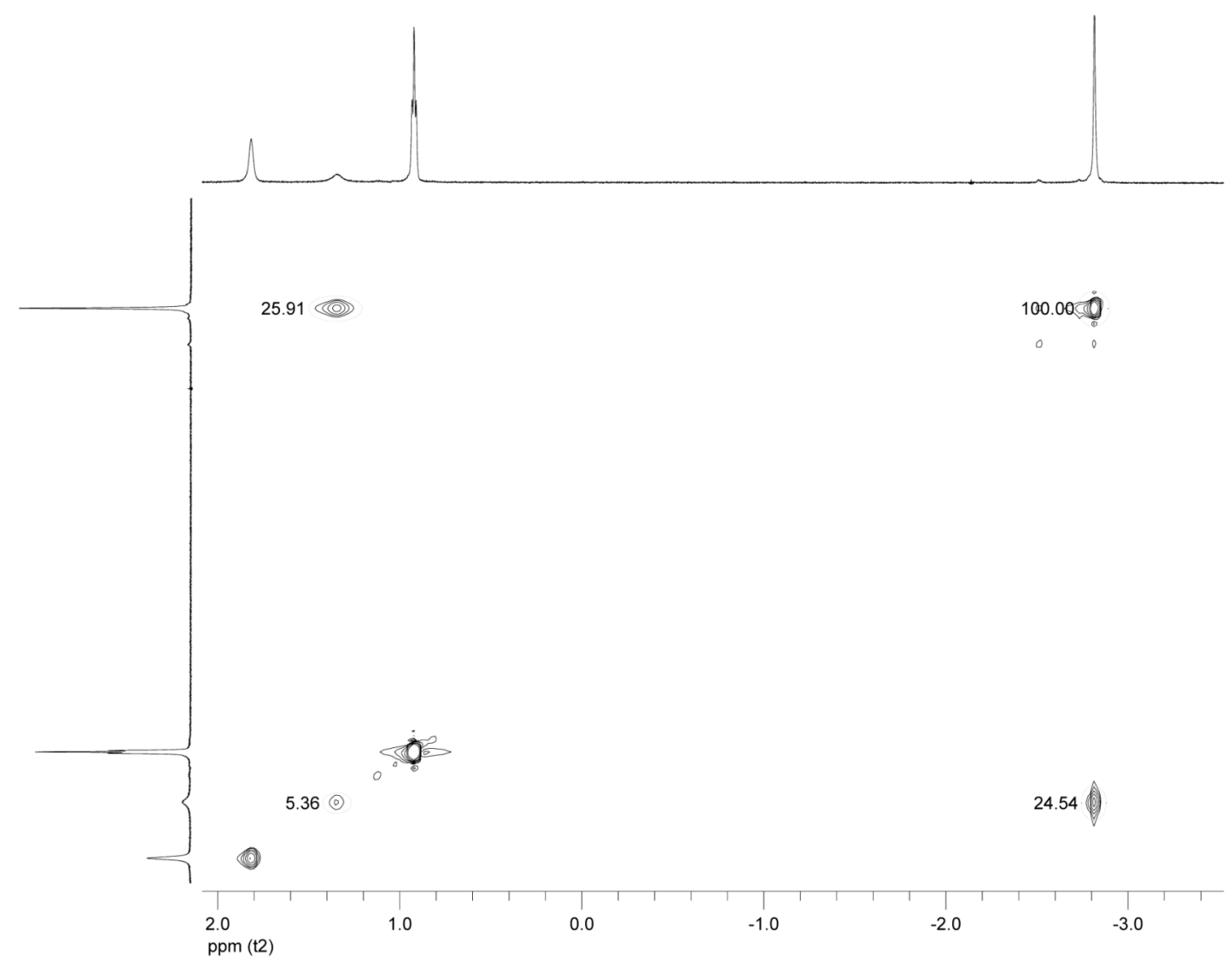


NOESY Spectrum of 1•cyclohexane, 0 ms mixing time:

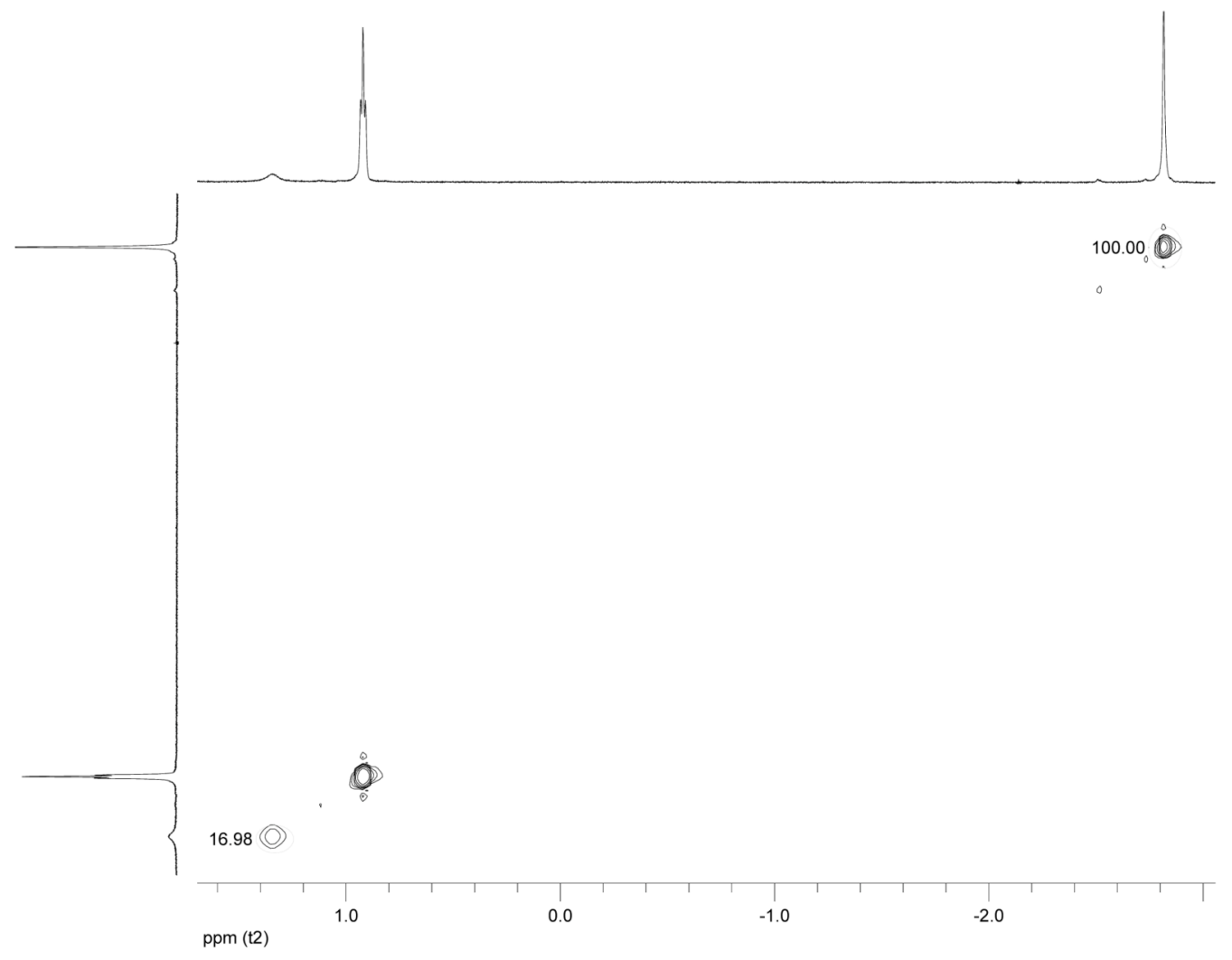


NOESY Spectrum of $2 \cdot$ cyclopentane, 350 ms mixing time:

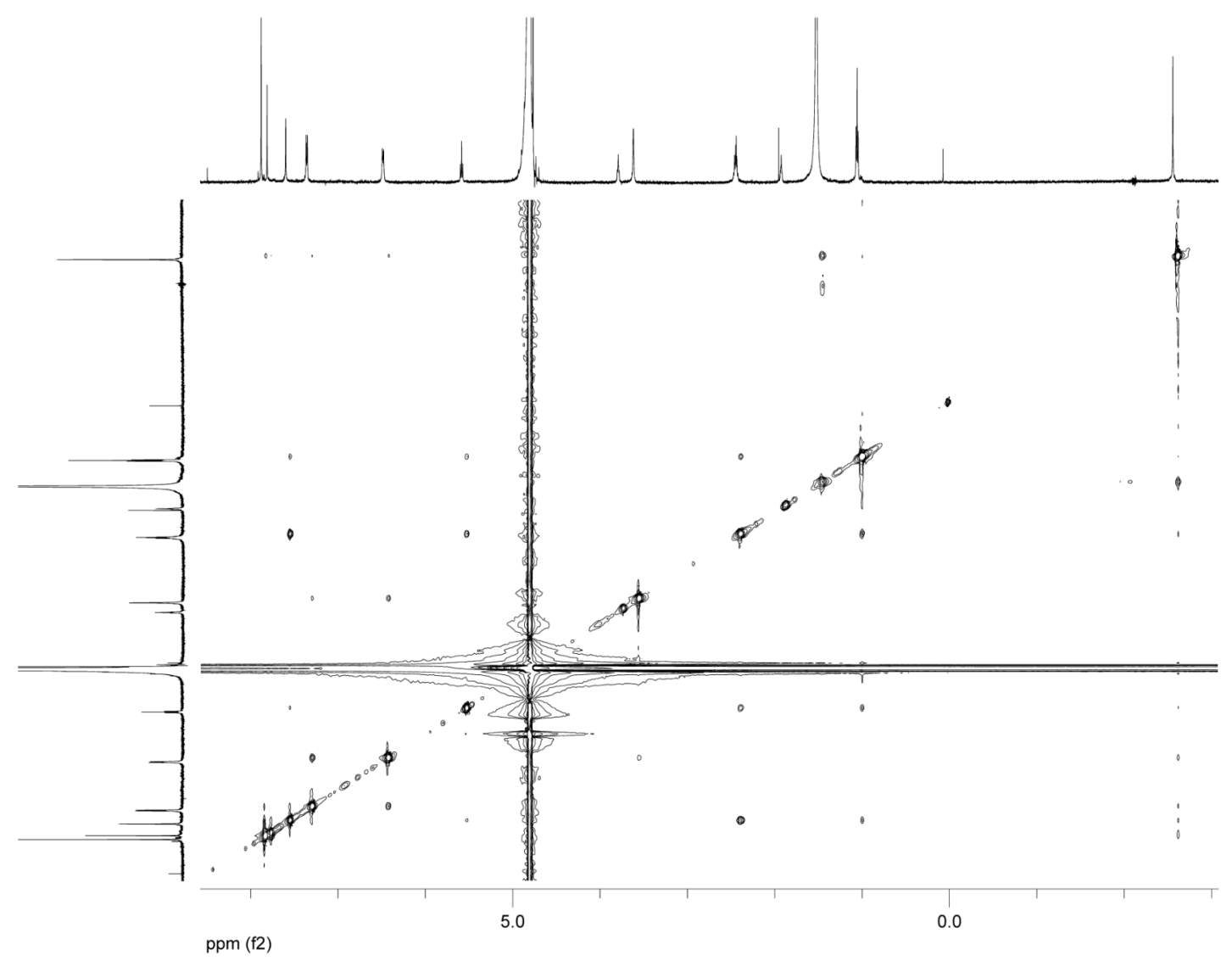

\section{References}

1) Trembleau, L.; Rebek, J. Science 2003, 301, 1219-1220.

2) Perrin, C. L.; Dwyer, T. J.; Chem. Rev. 1990, 90, 935-967.

3) Zolnai, Z.; Juranic, N.; Vikic-Topic, D.; Macura, S.; J. Chem. Inf. Comput. Sci., 2000, $40,611-621$. 